\title{
ARTICLE
}
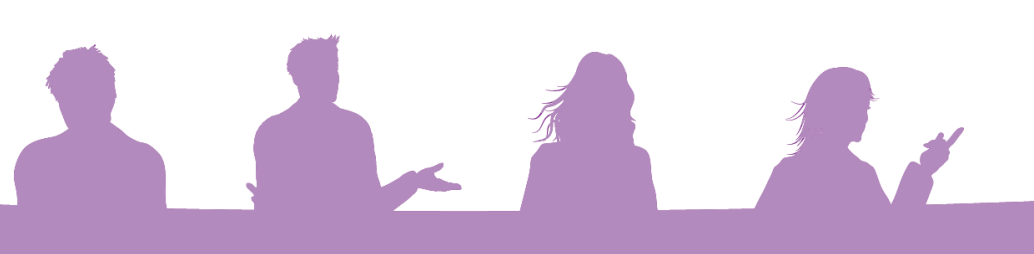

\section{The burden of untreated mental disorders in KwaZulu-Natal Province - mapping the treatment gap}

\author{
J K Burns, PhD \\ Department of Psychiatry, Nelson R Mandela School of Medicine, University of KwaZulu-Natal, Durban, South Africa
}

Corresponding author:J K Burns (burns@ukzn.ac.za)

Background. Low- and middle-income countries carry the major burden of mental disorders, yet owing to a significant lack of resources, they experience a 'treatment gap' in the range of $75-85 \%$.

Methods. Epidemiological data on mental disorders in South Africa, national census data and locally developed models for establishing treatment needs were used to calculate expected annual acute admissions and inpatient care, as well as expected annual ambulatory visits in KwaZulu-Natal (KZN) Province, South Africa. These were compared with actual acute admission and inpatient care rates as well as actual ambulatory visits to mental health services in the province, derived from the District Health Information Systems. These comparisons allowed an estimation of the treatment gap for mental disorders in the province.

Results. Approximately 956000 adults were estimated to live with mental disorders in KZN. Only 19.8\% (10 620) of expected admissions (53 623) took place during the one-year reporting period; while the total number of acute inpatient days accounted for $26.1 \%$ of the expected number. Average length of stay (ALOS) for acute admissions was longer (21 days) than the expected ALOS (16 days). At the recommended level of $30 \%$ coverage, ambulatory visits to mental health facilities accounted for $21 \%$ of the expected visits during the one-year period. Conclusion. In keeping with previous estimates, these results provide evidence that the 'treatment gap' for acute inpatient and ambulatory mental healthcare in $\mathrm{KZN}$ is $\sim 80 \%$. This rate is similar to the estimated mental health resource gap in the province, suggesting that gross inadequacies in mental health service provision translate directly into major unmet needs for those living with mental disorders.

S Afr J Psych 2014;20(1):6-10. DOI:10.7196/SAJP.499

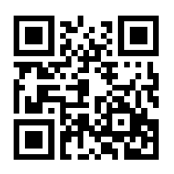

Mental disorders are common and responsible for increased mortality due to suicide and reduced life expectancy, considerable individual and collective suffering, significant loss of social and occupational functioning and productivity, and extensive disability. Moreover, they are a major burden on caregivers and families. Mental and neurological disorders are responsible for $\sim 14 \%$ of the global burden of disease and $30 \%$ of disability-adjusted life-years. ${ }^{[1]}$ It is anticipated that this will increase over the next few decades and that low- and middle-income countries (LAMICs) are likely to experience a disproportionate increase in burden due to mental disorders as they pass through the epidemiological transition.

Against this backdrop, there is a huge 'treatment gap' between the burden of mental disorders and the resources and services available 
to manage them. ${ }^{[2]}$ This is especially evident in LAMICs, with the World Health Organization (WHO) estimating that only a minority of those suffering from mental disorders ever receive any treatment. A study in Belize, for example, reported that $63 \%$ of individuals with schizophrenia, $89 \%$ of those with affective conditions and $99 \%$ of those with anxiety conditions were untreated. ${ }^{[3]}$ The WHO Mental Health Survey conducted in 14 countries found that the percentage of individuals with serious disabilities who received no treatment was 76 - 85\% in LAMICs and 35 - 50\% in high-income countries. ${ }^{[4]}$ Funding for mental health is notoriously poor; more than two-thirds of the world's population lives in countries that spend $<1 \%$ of their total public sector health budget on mental health services. ${ }^{[5,6]}$ Sadly, Africa exemplifies this: of the 19 African countries for which data are available, 15 spend $<1 \%$ of their health budgets on mental health. ${ }^{[6]}$

The South African Stress and Health (SASH) study, which was part of the WHO World Mental Health (WMH) Survey Initiative conducted between 2002 and 2004, reported results of a populationbased household survey of common mental disorders, surveying 4351 adults throughout South Africa (SA). ${ }^{[7,8]}$ According to findings of the SASH study, the 12-month prevalence of any common mental disorder (Diagnostic and Statistical Manual of Mental Disorders (DSM)-IV criteria) was $16.5 \%$ (and the lifetime prevalence $30.3 \%$ ), with the most common disorders being agoraphobia (4.8\%), major depressive disorder (MDD) (4.9\%) and alcohol abuse or dependence (4.5\%). The authors observed that the estimated prevalence of substance abuse in SA (5.8\%) was at least twice as high as that in other WMH countries, with the exception of Ukraine. With a suicide rate of 15.4/100 000, SA is ranked 22nd in the world. ${ }^{[9]}$ Notably, the SASH study reported that $75 \%$ of people with common mental disorders in SA do not receive any treatment. ${ }^{[8]}$

In the current study, best available prevalence data for mental disorders from SA studies (including the SASH study) were used to estimate the burden of mental disorders in KwaZulu-Natal (KZN) Province. Data on adult acute mental health inpatient and ambulatory service usage in KZN are presented and compared with expected service use based on published norms by Lund and Flisher; ${ }^{[10,11]}$ allowing for mapping of the mental health treatment gap in the province.

\section{Methods}

Literature reporting prevalence rates of mental disorders in adults in SA was reviewed and, for each disorder reported upon, a best estimate of prevalence was identified. These rates were then applied to the adult population of KZN (reported in the 2011 national census) to estimate the number of individuals affected by each disorder. Note: in this study, 'adult' refers to individuals aged $\geq 15$ years.

For acute inpatient care, expected admissions and expected total number of inpatient days were calculated using the method described by Lund and Flisher, as further detailed. ${ }^{[10]}$

Firstly, the expected number of severe cases was calculated as: $100 \%$ of those with schizophrenia and non-affective psychosis; $80 \%$ of those with bipolar disorder; $20 \%$ of those with major depressive disorder (MDD); and 5\% of those with anxiety disorders. Of these severe cases, the proportion in need of acute inpatient care per year was calculated as: $50 \%$ of those with schizophrenia and non-affective psychosis; $30 \%$ of those with bipolar disorder; $5 \%$ of those with MDD; and 5\% of those with anxiety disorders. Thus, the total number of expected acute admissions in one year could be calculated and compared with the actual number of acute admissions to psychiatric services in KZN, as reported in the District Health Information Systems (DHIS) for the 2010/2011 reporting year.

Next, using the average length of stay for each disorder, as recommended by Lund and Flisher, ${ }^{[10]}$ the expected total number of acute inpatient days was calculated and compared with the actual number of acute inpatient days within psychiatric services in KZN, as reported in the DHIS for the 2010/2011 reporting year.

Ambulatory service usage, which includes outpatient visits to primary healthcare clinics, satellites, mobile facilities and community health centres, as well as outpatient emergency services in hospitals, was calculated as follows:

First, the total number of individuals in need of ambulatory services in one year was calculated, with adjustments for comorbidity based on the method described by Lund and Flisher. ${ }^{[1]}$ This number was calculated at minimum coverage, according to the formula provided in the guidelines for primary healthcare services in SA, as follows: $50 \%$ of those with schizophrenia or bipolar disorder; $30 \%$ of those with MDD or post-traumatic stress disorder (PTSD); $20 \%$ of those with panic disorder, agoraphobia or social phobia; and $10 \%$ of those with generalised anxiety disorder (GAD).

Subsequently, the total number of expected ambulatory patient visits in one year was calculated based on the following formulae recommended by Lund and Flisher: ${ }^{[11]}$ schizophrenia and bipolar disorder - monthly visits for 12 months (12 visits per patient); MDD - every 2 weeks for 6 months (12 visits per patient); panic and agoraphobia - every 2 weeks for 3 months ( 6 visits per patient); social phobia and GAD - every 2 weeks for 2 months ( 4 visits per patient); and PTSD - every 2 weeks for 4 months ( 8 visits per patient).

Finally, the total number of expected ambulatory patient visits in one year was compared with the actual number of ambulatory patient visits in KZN reported in the DHIS for the 2010/2011 reporting year.

\section{Results}

\section{Prevalence of mental disorders in adults}

Table 1 shows the data on 12-month prevalence rates for mental disorders in SA based on reviewed studies. Note, an asterix indicates the prevalence rate used in the current study.

\section{Acute admissions}

Table 2 shows the expected number of individuals requiring acute inpatient care in one year in KZN. Assuming that each individual has one admission per year, the total number of expected admissions to psychiatric services in one year was 53 623. The actual number of admissions in KZN during the 2010/2011 reporting year was 10 620 (4 046 in district hospitals, 4219 in regional hospitals and 2355 in psychiatric hospitals.) The ratio of actual to expected number of admissions was $19.8 \%$.

\section{Acute inpatient days}

A total of 846226 acute inpatient days was expected within psychiatric services in KZN in one year (Table 3 ). The actual number during the 2010/2011 reporting year was 220839 days (43602 in district hospitals, 59217 in regional hospitals and 118020 in psychiatric hospitals). The 


\section{ARTICLE}
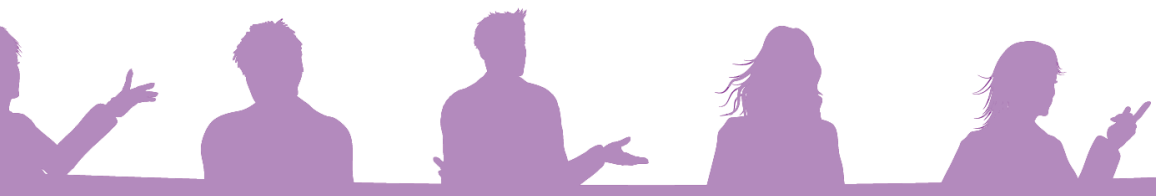

ratio of actual to expected number of acute inpatient days was $26.1 \%$. Note: the average length of stay (ALOS) for acute inpatient care

during this period averaged 21 days ( 11 days at district hospitals; 14 days at regional hospitals; and 50 days at psychiatric hospitals).

Table 1. Twelve-month prevalence of mental disorders in adults in SA

\begin{tabular}{|c|c|c|}
\hline Study & Sample & Prevalence, $\%$ \\
\hline \multicolumn{3}{|l|}{ MDD } \\
\hline Williams et al. ${ }^{[7]}$ & 4351 adults; household survey & $4.9^{*}$ \\
\hline Bhagwanjee et al. ${ }^{[12]}$ & 354 community-based rural adults & 4.8 \\
\hline \multicolumn{3}{|l|}{ Anxiety disorders } \\
\hline Williams et al. ${ }^{[7]}$ & 4351 adults; household survey & $8.1^{*}$ \\
\hline \multicolumn{3}{|l|}{ GAD } \\
\hline Williams et al. ${ }^{[7]}$ & 4351 adults; household survey & $1.4^{*}$ \\
\hline Bhagwanjee et al. ${ }^{[12]}$ & 354 community-based, rural adults & 3.7 \\
\hline \multicolumn{3}{|l|}{ PTSD } \\
\hline Williams et al..$^{[7]}$ & 4351 adults; household survey & $0.6^{*}$ \\
\hline \multicolumn{3}{|l|}{ Substance use disorders } \\
\hline Williams et al..$^{[7]}$ & 4351 adults; household survey & 5.8 \\
\hline \multicolumn{3}{|l|}{ Alcohol use disorders } \\
\hline Williams et al. ${ }^{[7]}$ & 4351 adults; household survey & 4.5 \\
\hline \multicolumn{3}{|l|}{ Personality disorders } \\
\hline Suliman et al. ${ }^{[13]}$ & 4351 adults; household survey & 6.8 \\
\hline \multicolumn{3}{|l|}{ Psychosis } \\
\hline Gureje et al. ${ }^{[14]}$ & $\begin{array}{l}1419 \text { adults; household survey } \\
\text { in Nigeria }\end{array}$ & $\begin{array}{l}2.1 \text { (lifetime prevalence) } \\
1.1{\text { (12-month prevalence })^{*}}^{\text {(12-mon }}\end{array}$ \\
\hline
\end{tabular}

\section{Ambulatory service usage}

The expected number of individuals requiring ambulatory services at minimum coverage (average $30 \%$ of full coverage) in one year in KZN was 254661 (of a total of 955814 adults with mental disorders) (Table 4).

The expected total number of ambulatory visits for mental healthcare in KZN in one year was calculated for each disorder and then summed according to the following formula proposed by Lund and Flisher: ${ }^{[11]}$

Annual visits $=$ number of cases $\times$ expected annual visits per patient

Note: these calculations were made for minimum coverage (results in Table 5). Thus, the expected total number of ambulatory visits in one year was 2395546 (with 9074 visits expected daily). The actual number of ambulatory visits to mental health services during the 2010/2011 reporting year was 506 206. The ratio of actual to expected number of visits was $21 \%$.

\section{Discussion}

This analysis, based on models published by Lund and Flisher, ${ }^{[10,11]}$ shows that both acute inpatient and ambulatory mental healthcare in KZN fell dramatically short of expected service provision based on population size and epidemiological data. In both cases,

Table 2. Expected number of individuals requiring acute inpatient care in one year in KZN

\begin{tabular}{|c|c|c|c|c|}
\hline Disorders & $\begin{array}{l}\text { One-year prevalence } \\
\%\end{array}$ & $\begin{array}{l}\text { Cases in adult } \\
\text { population } \\
n\end{array}$ & $\begin{array}{l}\text { Expected severe } \\
\text { adult cases } \\
n(\%)\end{array}$ & $\begin{array}{l}\text { Number in need of acute } \\
\text { inpatient care per year } \\
n(\%)\end{array}$ \\
\hline Schizophrenia and non-affective psychosis & 1.0 & 66840 & $66840(100)$ & $33420(50)$ \\
\hline Bipolar disorder & 1.0 & 66840 & $53472(80)$ & $16042(30)$ \\
\hline Major depression & 4.2 & 280728 & $56146(20)$ & $2807(5)$ \\
\hline Anxiety disorders & 8.1 & 541405 & $27070(5)$ & $1354(5)$ \\
\hline Total & & 955813 & 203528 & 53623 \\
\hline
\end{tabular}

Table 3. Expected number of acute inpatient days in one year in KZN

\begin{tabular}{llll}
\hline Disorder & $\begin{array}{l}\text { In need of acute inpatient } \\
\text { care per year, } \boldsymbol{n}\end{array}$ & $\begin{array}{l}\text { Average length of stay } \\
\text { (days) }\end{array}$ & $\begin{array}{l}\text { Number of inpatient } \\
\text { days per year, } \boldsymbol{n}\end{array}$ \\
\hline Schizophrenia and non-affective psychosis & 33420 & 16 & 534720 \\
Bipolar disorder & 16042 & 14 & 224588 \\
Major depression & 2807 & 30 & 84210 \\
Anxiety disorders & 1354 & 2 & 2708 \\
Total & 53623 & 16 & 846226 \\
KZN = KwaZulu-Natal. & & &
\end{tabular}


the 'treatment gap' is in the region of $80 \%$, which lends support to findings of the SASH study indicating that $\sim 75 \%$ of individuals with common mental disorders in SA do not receive any treatment. ${ }^{[8]}$ Interestingly, this treatment gap also correlates closely with the recent finding from KZN that the province has only $25 \%$ of the psychiatric beds and $25 \%$ of the psychiatrists required to comply with national norms. ${ }^{[15]}$ The same study reported that budget increases to psychiatric hospitals in KZN over the 5-year period 2005 - 2010 were approximately one-fifth of the increases received by general hospitals.

Taken together, the findings of the study by Burns ${ }^{[15]}$ and the findings of the current study suggest that there is a close correlation between resources committed to mental healthcare and the services rendered to the public. This is by no means new insight, as the links between inadequate resource provision and the 'treatment gap' for people living with mental disorders have been highlighted extensively in both international and national literature. ${ }^{[2,16-18]}$

The fact that the gap is slightly less for number of acute inpatient days compared with number of acute admissions can be explained by the fact that the average length of stay within psychiatric services during the assessed period was slightly longer (21 days) than the expected average length of stay (16 days). Thus, individuals who were admitted to services received more care than expected, possibly at the expense of additional individuals who could not access inpatient care at all. It is well recognised throughout SA that the widespread shortage of psychiatric beds translates daily into scenarios where clinicians struggle to secure space for their patients within psychiatric facilities.

The reality of a significant treatment gap in KZN begs the question: where are all these people with mental disorders obtaining help? Or, are the majority living with their distress, without any access to care of any form? This highlights the importance of other forms of care - formal or informal - within resource-scarce regions. In many LAMIC contexts, traditional healers partially fill this gap and need to be engaged as important partners in providing some form of care for those with mental disorders. In KZN, a significant proportion of those experiencing mental disorders consult traditional healers. For example, in their study of hospitalised patients with first-episode psychosis, Burns et al. ${ }^{[19]}$ reported that $39 \%$ of patients consulted traditional healers prior to seeking treatment from formal health services. Notably, consultation with traditional healers was associated with delays in accessing psychiatric care, and the authors concluded that this finding 'serves to reinforce the importance of developing

Table 4. Number of individuals requiring ambulatory services at minimum and full coverage in KZN

\begin{tabular}{|c|c|c|c|c|}
\hline Disorder & $\begin{array}{l}\text { Prevalence adjusted for } \\
\text { comorbidity }^{*}\end{array}$ & $\begin{array}{l}\text { Total in population } \\
N\end{array}$ & $\begin{array}{l}\text { Minimum coverage } \\
\text { (at } 30 \% \text { coverage) }\end{array}$ & $\begin{array}{l}\text { Full coverage } \\
\text { (at } 100 \% \text { coverage) }\end{array}$ \\
\hline Schizophrenia & 1 & 66840 & 33420 & 66840 \\
\hline Bipolar disorder & 1 & 66840 & 33420 & 66840 \\
\hline MDD & 4.2 & 280728 & 84218 & 280728 \\
\hline Panic disorder & 0.7 & 46788 & 9358 & 46788 \\
\hline Agoraphobia without panic & 4.1 & 274045 & 54809 & 274045 \\
\hline Social phobia & 1.6 & 106945 & 21389 & 106945 \\
\hline GAD & 1.2 & 80208 & 8021 & 80208 \\
\hline PTSD & 0.5 & 33420 & 10026 & 33420 \\
\hline Total & 14.3 & 955814 & 254661 & 955814 \\
\hline
\end{tabular}

Table 5. Annual and daily patient visits required for ambulatory mental healthcare in KZN

\begin{tabular}{|c|c|c|c|c|}
\hline \multirow[b]{2}{*}{ Disorder } & \multirow[b]{2}{*}{ Expected annual visits/person } & \multicolumn{3}{|c|}{ Minimum coverage (at $30 \%$ ) } \\
\hline & & Cases, $n$ & Total annual visits, $n$ & DPVs \\
\hline Schizophrenia & 12 & 33420 & 401040 & 1519 \\
\hline Bipolar disorder & 12 & 33420 & 401040 & 1519 \\
\hline MDD & 12 & 84218 & 1010616 & 3828 \\
\hline Panic disorder & 6 & 9358 & 56148 & 213 \\
\hline Agoraphobia without panic & 6 & 54809 & 328854 & 1246 \\
\hline Social phobia & 4 & 21389 & 85556 & 324 \\
\hline GAD & 4 & 8021 & 32084 & 122 \\
\hline PTSD & 8 & 10026 & 80208 & 304 \\
\hline Total & & 254661 & 2395546 & 9074 \\
\hline
\end{tabular}


positive collaborative links between traditional and formal health services' in attempting to improve pathways to care for individuals with disabling mental disorders.

The results of the current study should be considered in light of several important limitations. Firstly, although the SASH study has provided us with good epidemiological data in SA, a number of mental disorders were not included in the study and prevalence rates for disorders such as psychosis and bipolar disorder were based on a best estimate derived from international literature. Secondly, the quality of the DHIS data upon which the actual service usage was based is questionable. We know that in many health facilities there are a number of barriers to efficient and accurate reporting that cast doubt on the reliability and validity of these data. Thirdly, in relation to ambulatory care, estimates of expected service usage were based on a minimum level of coverage (averaging $30 \%$ ), thus very likely underestimating the expected service needs and the extent of the treatment gap for ambulatory mental healthcare. Finally, and perhaps most importantly, this analysis did not take into account the contribution of the private sector services in SA in managing the burden of mental ill-health in the country. Private mental healthcare is a significant entity and omission of these data means that the stated estimates of the treatment gap are very likely overestimates. However, the private sector provides no more than $15 \%$ of medical care in $\mathrm{SA} ;{ }^{[20]}$ thus, the anticipated reduction in the treatment gap following the inclusion of private sector data is unlikely to be substantial.

\section{Conclusion}

This study supports previous estimates of the treatment gap in SA and shows the merit and usefulness of modeling mental health service needs, as in the case of Lund and Flisher's ${ }^{[10,11]}$ work. Health authorities and planners should pay heed to the gross inadequacy of mental health service provision in the region and appreciate the fact that these inadequacies translate directly into major unmet needs for those living with mental disorders.

\section{References}

1. Prince M, Patel V, Saxena S, et al. No health without mental health. Lancet 2007;370(9590):859877. [http://dx.doi.org/10.1016/S0140-6736(07)61238-0]

2. Saxena S, Thornicroft G, Knapp M, Whiteford H. Resources for mental health: Scarcity, inequity, an inefficiency. Lancet 2007;370(9590):878-889. [http://dx.doi.org/10.1016/S0140-6736(07)61239-2]

3. Bonander J, Kohn R, Arana B, et al. An anthropological and epidemiological overview of mental health in Belize. Transcultural Psychiatry 2000;37:57-72.

4. WHO World Mental Health Survey Consortium. Prevalence, severity, and unmet need for treatment of mental disorders in World Health Organization World Mental Health surveys. JAMA 2004:291(21):2581-2590.

5. World Health Organization. Mental Health Fact Sheet 2009. Geneva: WHO, 2009. http://www who.int/mental_health/en/index.html (accessed 1 September 2013).

6. Shah AA, Beinecke RH. Global mental health needs, services, barriers and challenges. Int J Menta Health 2009;38(1):14-29.

7. Williams DR, Herman A, Stein DJ, et al. Twelve-month mental disorders in South Africa Prevalence, service use and demographic correlates in the population-based South African Stress and Health Study. Psychol Med 2008;38(2):211-220. [http://dx.doi.org/10.1017/ S0033291707001420]

8. Seedat S, Stein DJ, Herman A, et al. Twelve-month treatment of psychiatric disorders in the South African Stress and Health Study (World Mental Health Survey Initiative). Soc Psychiatry Psychiat Epidemiol 2008;43(11):889-897. [http://dx.doi.org/10.1007/s00127-008-0399-9]

9. Burrows S, Laflamme L. Suicide mortality in South Africa: A city-level comparison across sociodemographic groups. Soc Psychiatry Psychiatr Epidemiol 2006;41(2):108-114.

10. Lund C, Flisher AJ. Norms for mental health services in South Africa. Soc Psychiatry Psychiat Epidemiol 2006;41:587-594. [http://dx.doi.org/10.1007/s00127-006-0057-z]

11. Lund C, Flisher AJ. A model for community mental health services in South Africa. Trop Med In Health 2009;14(9):1040-1047. [http://dx.doi.org/10.1111/j.1365-3156.2009.02332.x]

12. Bhagwanjee A, Parekh A, Paruk Z, Petersen I, Subedar H. Prevalence of minor psychiatric disorder in an adult African rural community in South Africa. Psychol Med 1998;28(5):1137-1147.

13. Suliman S, Stein DJ, Williams DR, Seedat S. DSM-IV personality disorders and their Axis correlates in the South African population. Psychopathology 2008;41(6):356-364. [http://dx.doi org/10.1159/000152377]

14. Gureje O, Olowosegun O, Adebayo K, Stein DJ. The prevalence and profile of non-affective psychosis in the Nigerian Survey of Mental Health and Wellbeing. World Psychiatry 2010;9(1):50-55

15. Burns JK. Mental health services funding and development in KwaZulu-Natal Province: A tale of inequity and neglect. S Afr Med J 2010;100:662-666.

16. Kohn R, Saxena S, Levav I, et al. The treatment gap in mental health care. Bull World Health Organ 2004;82(11):858-866.

17. Lancet Global Mental Health Group. Scale up services for mental disorders: A call for action Lancet 2007;370(9594):1241-1252. [http://dx.doi.org/10.1016/S0140-6736(07)61242-2]

18. Burns JK. The mental health gap in South Africa: A human rights issue. The Equal Rights Review 2011;6:99-114.

19. Burns JK, Jhazbhay K, Emsley RA. Causal attributions, pathway to care and first-episode psychosis: A South African perspective. Int J Soc Psychiatry 2011;57(5):538-545. [http://dx.doi org/10.1177/0020764010390199

20. McIntyre D. Private Sector Involvement in Funding and Providing Health Services in South Africa: Implications for Equity and Access to Health Care. EQUINET Discussion Paper Series 84 Grahamstown: Health Economics Unit (UCT), ISER Rhodes University, and Harare: EQUINET, 2010. 